\title{
A percepção dos docentes e técnico-administrativos em educação acerca do processo de aposentadoria
}

\section{The perception of teachers and technical staff in education about the retirement process}

\author{
Frederico Guedes Pena, Priscilla de Oliveira Reis Alencastro, Aline Sarturi Ponte, \\ Kayla Araújo Ximenes Aguiar Palma
}

\section{RESUMO}

Introdução: A aposentadoria pode ser vivenciada de diferentes formas pelos sujeitos que passam por este processo, para algumas pessoas pode significar um status de inatividade pelo trabalhador que retira-se do meio laboral, para outros pode ser um momento de liberdade, como um espaço para poder desenvolver novos projetos. Objetivo: Analisar a percepção dos docentes e técnico-administrativos em educação de uma universidade localizada no interior do estado Rio Grande do Sul acerca do processo de aposentadoria. Metodologia: Trata-se de um estudo de abordagem qualitativa do tipo descritiva. Foram convidados para participar desta pesquisa servidores de uma Universidade pública do interior do Rio Grande do Sul. Para a coleta de dados foi utilizada a metodologia bola de neve e os participantes responderam a um questionário auto aplicado. A análise dos dados foi realizada a partir da Análise de Conteúdo. Resultados: Os resultados estão apresentados em três categorias, são elas: representações da aposentadoria, sentimentos frente a aposentadoria e planejamento para a aposentadoria. Durante o estudo observou-se que a aposentadoria é uma oportunidade de libertação, sensação de alívio, de dedicação para outras esferas da vida, de viver com mais qualidade, a maioria dos participantes referiu estar preparado para se aposentar e referem sentimento de dever cumprido, relacionando este momento a novas descobertas e aprendizagens sobre 0 que fazer com o tempo livre. Considerações finais: A partir dos dados pode-se compreender a representação social do trabalho e o impacto do processo de aposentadoria. Este momento é marcado por sentimentos de libertação, de alívio, novas descobertas e o desejo viver com mais qualidade, sendo assim, torna-se importante refletir sobre a preparação para o processo de aposentadoria.

PALAVRAS-CHAVE: Categoria de Trabalho; Planejamento; Aposentadoria.

Federal de Saúde Maria

Endereço para correspondência:

Rua: Faixa Nova de Camobi, km

09 - Campus Universitário

Bairro: Camobi

Cidade: Santa Maria

Estado: Rio Grande do Sul

CEP: 97 105-900

Data de Submissão:

$31 / 03 / 2020$

Data de aceite:

10/09/2020

Conflito de Interesse: Não há conflito de interesse

\section{(c)) BY-NC-ND} To analyze the perception of teachers and technical-administrators in education of a university located

\section{ABSTRACT}

Introduction: Retirement can be experienced in different ways by the subjects who go through this process, for some people it can mean a status of inactivity by the worker who withdraws from the work environment, for others it can be a moment of freedom, as a space to develop new projects. Objective: in the interior of the state of Rio Grande do Sul about the retirement process. Methodology: This is a qualitative approach study of the descriptive type. Servants of a public university in the interior of Rio Grande do Sul were invited to participate in this research. For data collection the snowball methodology was used and the participants answered a self-applied questionnaire. The data analysis was carried out from the Content Analysis. Results: The results are presented in three categories: representations of retirement, feelings towards retirement and planning for retirement. During the study it was observed that retirement is an opportunity for liberation, feeling of relief, dedication to other spheres of life, living with more quality, most of the participants reported being prepared to retire and refer to a feeling of duty fulfilled, relating this moment to new discoveries and learning about what to do with free time. Final considerations: From the data one can understand the social representation of work and the impact of the retirement process. This moment is marked by feelings of liberation, relief, new discoveries and the desire to live with more quality, so it becomes important to reflect on the preparation for the retirement process.

KEYWORDS: Occupational Groups; Planning; Retirement. 


\section{INTRODUÇÃO}

A etimologia da palavra aposentadoria, refere-se a dois conceitos, o primeiro, retirar-se aos aposentos ou recolhimento ao espaço de não trabalho, e o segundo, jubilamento. O primeiro termo está associado ao status de abandono, inatividade ou finitude; enquanto o segundo, a uma concepção de recompensa, contentamento e otimismo 1 . Para Santos, os trabalhadores entendem e vivenciam esse ciclo de diferentes formas. Alguns vivem momentos de crise e sofrem com o possível rompimento dos laços de amizade, da convivência diária, da identidade profissional construída ao longo da carreira, enquanto outros, vivem momentos de liberdade, pois estes não limitam suas identidades somente ao papel ocupacional partindo de uma construção de projeto de vida pós-carreira1.

O processo de aposentadoria é uma fase de mudanças e que pode gerar ansiedades no indivíduo, pois este depara-se com o enfrentamento de estigma social, estereótipos, preconceitos, que associa a aposentadoria ao conceito de velho, não produtivo. Ressalta-se que à mudança demográfica tem contribuído para desconstrução deste conceito². Deste modo, o processo de aposentadoria ocorre de maneira heterogênea dentre os trabalhadores, não existe uma fórmula para vivenciar este processo, uma vez que cada indivíduo tem os seus desejos e expectativas entre querer continuar ou retirar-se do ambiente laboral ${ }^{3}$.

O planejamento a longo prazo da aposentadoria é importante para uma satisfatória aceitação deste momento, mas sabe-se que muitos trabalhadores não se preocupam em construir este planejamento ao longo do período produtivo. Sendo assim, o presente trabalho tem o objetivo de analisar a percepção dos docentes e técnico-administrativos em educação de uma universidade localizada no interior do estado Rio Grande do Sul acerca do processo de aposentadoria.

\section{MÉTODO}

O estudo utilizou a abordagem qualitativa. Respeitou a Resolução n 466/12 do Conselho Nacional de Saúde, aprovado pelo Comitê de Ética em Pesquisa da Universidade onde ocorreu o estudo, sob número 86696418.1.0000.5346. Este considerou os seguintes critérios de inclusão: servidores públicos (Docentes e Técnico-Administrativos em Educação - TAE) que estivessem próximo do período de se aposentar ( 5 anos pré-término das atividades laborais).

Para contatar os participantes, utilizou-se a metodologia de amostragem "bola de neve". Incialmente foram necessários informantes chaves (nomeados de sementes), a fim de localizar as pessoas com perfil para participar do estudo e solicitou-se a estes que indicassem novas pessoas com as características desejadas, e assim, a amostra tem a possibilidade de aumentar a cada entrevista ${ }^{4}$.

Para coleta de dados utilizou-se um questionário auto aplicado, com questões sociodemográficas (sexo, data de nascimento, escolaridade e cargo) e questões sobre entendimento, preparação, preocupações e planejamento para a 
aposentadoria e conhecimento do programa de preparação para a aposentadoria ofertado pela Instituição.

Os questionários foram aplicados individualmente, os participantes responderam por escrito e o tempo de coleta foi aproximadamente 15 minutos. Para preservar o anonimato dos participantes, estes serão identificados como: Participante A, Participante B, e assim sucessivamente.

Participaram deste estudo oito servidores públicos federais de uma Universidade Pública localizada no interior do estado do Rio Grande do Sul, sendo seis mulheres e dois homens, com idade entre 52 e 65 anos. Em relação a escolaridade/titulação, três tinham ensino superior, dois pós-doutorado, um tinha especialização, um mestrado e um doutorado. Destes cinco eram TAE e três Docentes.

Quadro 1 - Caracterização dos participantes.

\begin{tabular}{|c|c|c|c|c|}
\hline Participantes & Sexo & Idade & Escolaridade/Titulação & Cargo \\
\hline A & Feminino & 54 & Especialização & TAE \\
\hline B & Feminino & $\mathrm{NI}$ & Ensino Superior & TAE \\
\hline C & Feminino & $\mathrm{Nl}$ & Ensino Superior & TAE \\
\hline D & Feminino & $\mathrm{NI}$ & Ensino Superior & TAE \\
\hline E & Feminino & 56 & Pós-doutorado & Docente \\
\hline F & Feminino & 52 & Mestrado & TAE \\
\hline G & Masculino & 65 & Pós-doutorado & Docente \\
\hline H & Masculino & 60 & Doutorado & Docente \\
\hline
\end{tabular}

Legenda: NI: Não Informado; TAE: Técnico-Administrativos em Educação. Fonte: elaborado pelos autores.

Para análise dos dados, utilizou-se Análise de Conteúdo, neste método o pesquisador deve compreender as características, estruturas ou modelos que estão por trás das expressões/mensagens. Devendo então, entender 0 sentido da comunicação, buscando as significações possíveis por meio ou ao lado daquilo que foi falado 5 .

\section{RESULTADO E DISCUSSÃO}

Com o processo de envelhecimento no ambiente de trabalho urge discutirmos o processo de aposentadoria e as percepções dos futuros aposentados, frente a este novo status social. Frente a isso há estudos como de Graeff ${ }^{6}$ que compreende a aposentadoria como um campo de conhecimento que sofre transformações coletivas nos diferentes modos de ser, pensar e agir. Segundo o autor "trata-se, na verdade, de uma matriz de pensamentos de senso comum inseridos em um contexto sociocultural e econômico maior"6 (p.22). Assim, as representações sociais da aposentadoria estão intimamente ligadas as percepções sociais estabelecidas como velhice, improdutividade, inutilidade, ou ainda, 
como liberdade e momento de novas oportunidades e maior qualidade de vida.

A partir dos dados foram criadas três categorias, são elas: 1) Representações da aposentadoria; 2) Sentimentos frente à aposentadoria e; 3) Planejamento quanto a aposentadoria.

\section{Categoria 1 - Representações da aposentadoria}

O momento da aposentadoria é considerado um momento de transição e como consequência pode gerar angústia, estresse, medo e insegurança. Além disso, socialmente há muitos preconceitos e estigmas relacionados a aposentadoria e ao indivíduo aposentado, podendo, muitas vezes, aumentar a sensação de inutilidade, improdutividade e solidão.

Nesta categoria, pretende-se refletir sobre como os participantes percebem o processo que estão vivendo, a compreensão do conceito de aposentadoria e o significado deste momento em suas vidas. A aposentadoria deve ser compreendida para além de um direito previdenciário, pois está se configura como um dos momentos mais críticos da vida adulta e envolve fatores psicológicos, sociais e econômicos ${ }^{7}$.

A partir das falas dos participantes, percebe-se que a aposentadoria surge como uma oportunidade de libertação, uma sensação de alívio, no que diz respeito principalmente à questão de cumprimento de horários, mas também é compreendida como um momento de liberdade, de novas escolhas, em contraste com a vida atual, conforme os relatos dos Participantes A, B e C.

"[...]Momento de libertação, sem horários para cumprir, ponto, normas e regras da chefia[...] Momento no qual a pessoa é dona do seu tempo, e é remunerada por isso." (Participante A, TAE).

"É o momento em que se completa o tempo de atuação na instituição/empresa e o servidor/funcionário adquire o direito de aposentar-se. A aposentadoria representa para mim uma liberdade: de tempo, de escolhas, de vida." (Participante B, TAE).

"[...]final das atividades de trabalho no local com remuneração. Libertação." (Participante C, TAE).

A aposentadoria, representa a oportunidade de dedicar seu tempo para outras esferas da vida que foram, em alguns momentos, deixadas de lado, pois a prioridade era o trabalho ${ }^{8}$. Segundo França et al., ${ }^{9}$ para alguns trabalhadores 
é a chance de, por fim, concretizar projetos que ainda não haviam sido executados por conta do tempo dedicado ao trabalho. O Participante $\mathrm{E}$, ressalta que é um momento de dar atenção à outras questões como o lazer e a família:

"[...]estabelecendo horários flexíveis e atendendo uma agenda mais dedicada ao lazer e a família." (Participante E, Docente).

Algumas pessoas tem na aposentadoria "a expectativa de "viver com mais qualidade", sem cobranças, sem hora marcada, sem estresse, com mais autonomia e o sentimento de dever cumprido"10:7. Deste modo, Venturini et al., ${ }^{11}$ afirmam que quando a aposentadoria é recebida pelas pessoas de maneira positiva, vista como um novo projeto de vida a ser desenvolvido, incluindo a família, lazer, atividades ocupacionais haverá melhor adaptação às mudanças biológicas, psicológicas e sociais deste processo. Assim, tendo maior compreensão e estando cientes das perdas, mas também dos possíveis ganhos que esta nova fase da vida pode proporcionar.

Foi possível perceber, que este momento além de representar libertação, configura-se como um momento o qual oportuniza a procura de uma outra atividade laboral fora do serviço público como mencionado pelos Participantes B e C. Também, estando associado a um momento de reflexão sobre si próprio, como exposto pelo Participante F.

[...]exercer outras atividades, outros desafios que não os fiz até agora. Necessidade de novos rumos na vida, mais adequados ao meu momento." (Participante B, TAE).

"Fim de uma etapa na vida profissional na instituição, o que não impede de começarmos outras atividades laborais fora." (Participante C, TAE).

"[...]período de maior reflexão." (Participante F, TAE).

Percebe-se no relato do participante $\mathrm{B}$ e $\mathrm{C}$, o desejo e a possibilidade de realizar outras atividades, ou novos desafios, que não foi realizado até o momento. Segundo Panozzo ${ }^{12}$,

[...] a aposentadoria pode vir a representar maior disponibilidade para o lazer ou para realizar atividades que foram postergadas durante longo tempo, em função das rotinas do trabalho. Nessa transição, ela pode representar oportunidades para o desenvolvimento pessoal, desde que sejam descobertas as potencialidades e fontes de prazer [...] (p. 39). 
Frente às falas dos participantes e as reflexões apresentadas pelos autores pode-se observar que, mesmo que o trabalhador saiba durante toda a sua vida produtiva que o momento da aposentadoria chegará, está só passa a ser um objetivo, quando se aproxima. Tal proximidade leva a diversas reflexões, podendo provocar um momento muito estressante e de muita expectativa ${ }^{13}$. A partir das falas foi possível perceber que a aposentadoria tem diversas representações para os Docentes e TAE, estes a associam o processo de aposentadoria ao final de um ciclo, a reflexão sobre si próprio, a libertação ou a crise e a oportunidade de desenvolver outras atividades e de dedicar mais ao lazer e a família.

\section{Categoria 2 - Sentimentos frente à aposentadoria}

Esta categoria, aborda questões relacionadas aos sentimentos dos trabalhadores que estão em processo de aposentadoria, associando os sentimentos encontrados entre os entrevistados com as representações sobre a aposentadoria em suas vidas. Sabe-se que o trabalho tem uma representação muito importante na vida das pessoas, segundo o que afirmam Lancman e Sznelwar ${ }^{14}$, o trabalho pode assumir um papel central na vida dos sujeitos, pois é possível perceber nele a mediação entre o singular e o coletivo, entre a subjetividade e o meio social.

Assim, é possível pensar nas possíveis implicações, sentimentos e transformações envolvidos que podem surgir no cotidiano dos trabalhadores no momento do desligamento da atividade laboral, ou, inclusive, no processo da transição de assumir um novo papel social. Porém, "a relação dos indivíduos com o trabalho é bastante diversa: para alguns ele é apenas um meio de sobrevivência, para outros uma fonte de prazer e de criatividade"15:14. Tal importância ou valorização do trabalho pode estar justificada, pelo fato das pessoas passarem grande parte de seu dia no ambiente laboral, sendo ele um veículo de identidade e gerador de pertencimento social ${ }^{16}$.

Entres os participantes, cinco referiram que se sentem preparados para aposentar-se, enquanto os outros três referiram que ainda não estão preparados. Os participantes que se sentem preparados para a aposentadoria referem em suas falas o sentimento de dever cumprido, de contribuição com o serviço público e com a sociedade, como apresentado nas falas dos participantes $B, D$ e $E$.

"Por sentir que já estou com o dever cumprido[...]" (Participante B, TAE).

"[...]porque já contribuí com trabalho e dedicação e a idade requer um pouco de descanso sem muita responsabilidade de cumprir horários rigorosos." (Participante $D, T A E)$. 
"[...]porque sinto que já dei minha parcela de contribuição ao serviço público e à sociedade em relação ao cargo que exerço na instituição[...]" (Participante E, Docente).

Sobre o sentimento de dever cumprido, como visto nos relatos, corrobora as discussões realizadas por Macedo et al. ${ }^{10} \mathrm{em}$ que a aposentadoria é vista como um direito do trabalhador garantida pelo cumprimento de seu dever frente a sociedade, sendo um vista como uma troca justa o recebimento do benefício como previsto em lei.

Os Participantes C, F e H, referem que não se sentem preparados para a aposentadoria. Estes ressaltam que não sabem como irão administrar esta nova fase, nem quais atividades vão desenvolver, tendo dúvidas sobre a vida de aposentado e referem o sentimento de não preparação para a aposentadoria.

"Acho que posso trabalhar mais um pouco e tenho muitas dúvidas como vai ser minha vida de aposentada." (Participante C, TAE).

"Porque ainda não decidi quais as coisas a serem feitas." (Participante F, TAE).

Primeiro, porque gosto (muito) de trabalhar; segundo, porque a minha vida é sinônimo de trabalho (até agora). Enfim, a minha vida, até agora, se resumiu à preparação para o trabalho, então, veio o trabalho; e, aí...". (Participante $\mathrm{H}$, Docente).

Rovida $^{17}$ ressalta que através do trabalho o homem planeja melhorar suas condições de vida, altera a natureza a sua volta e também muda a si mesmo. Sendo assim, torna-se importante refletir sobre a transição trabalho-aposentadoria sofrida pelos trabalhadores. Asforth ${ }^{18}$ reflete sobre esta transição sob a perspectiva da teoria dos papéis, dizendo que as pessoas, ao longo da vida, podem assumir diferentes papéis (filho, marido, esposa, trabalhador, aposentado), identificados em diversos contextos, seja na família, na organização ou na sociedade. A transição dos papéis se dá quando ocorre uma transição na mesma época (micro) ou, em diferentes momentos da vida (macro); a aposentadoria no caso, está dentro do macro, que é o momento quando o trabalhador decide retirar-se de um papel para assumir outro. Assim, não representa apenas um momento de adaptação, mas, de desenvolvimento, no que se refere à adoção de novos papéis ${ }^{19}$.

A partir da fala do Participante $\mathrm{H}$ percebe-se que este dedicou parte de sua vida para a preparar-se para a 
atividade laboral e após dedicou-se ao trabalho. Observa-se que o trabalho significou durante muito tempo um papel importante e principal na sua vida, e pensar no novo papel a ser assumido, como aposentado, pode ser um processo de transição difícil. Para Rodrigues et al. ${ }^{2}$, o modo de produção capitalista aliena o trabalhador dentro do seu processo de produção e a aposentadoria é experienciada como a perda de sua identidade e do próprio sentido da vida, sendo valorizada a produção e a depreciação do indivíduo aposentado.

Ressalta-se que muitos trabalhadores ainda não se sentem preparados para a aposentadoria, pois estes vivenciam esta transição como um momento de crise. Esta é causada por diversos fatores, são eles: o afastamento do processo e do ambiente de trabalho, do convívio diário, das relações e laços construídos no decorrer da vida. Além destes fatores, os trabalhadores deparam-se com o estigma que associa a condição de aposentado à inatividade ${ }^{1}$. Para Zanelli e Silva ${ }^{20}$ a associação da pessoa aposentada a inatividade está relacionado a categoria social que estes ocupam nos registros formais, denominada de "inativos." O conceito de inativo opõe-se à mobilidade ou movimento, essência da própria vida. Frente a esta reflexão pode-se observar que a denominação formal "inativos" pode ser um fator gerador de barreiras para as pessoas aposentadas, pois o conceito da palavra transmite uma ideia de que 'se você não mais trabalha, deixa de ter importância ${ }^{20}$.

Quando questionado sobre as principais preocupações, cinco participantes apresentam preocupações em relação à aposentadoria e três referiram não ter preocupações ainda. As principais preocupações expostas pelos participantes foram: o tédio, ficar na ociosidade, acabar por não conseguir desenvolver o que hoje é planejado, perder o vínculo conquistado com os colegas de trabalho, o afastamento das pessoas e a possibilidade de adoecimento, conforme apresentado nas falas dos Participantes $\mathrm{B}$ e E:

"Realmente, tenho a preocupação de ficar acomodada em casa e acabar por não fazer o que, hoje, planejo" (Participante B, TAE).

"[...]ficar na ociosidade, [...]perder o vínculo de amizades que conquistei ao longo dos anos" (Participante E, Docente).

Macedo et al., ${ }^{10}$ ressalta que o ócio pode estar associado à inatividade, acomodação ou possível depressão, reafirmado pela expectativa de não se ter atividades que substituam o trabalho. Ainda, o Participante $F$ fala que tem como preocupação 0 ,

"Afastamento das pessoas, não conseguir desenvolver outra atividade, possibilidade de adoecimento." (Participante F, TAE). 
Os participantes que referiram não ter preocupações veem o momento da aposentadoria como um recomeço ou não se preocupam muito, conforme ressaltam os Participantes Ae G.

"Não tenho preocupações, hoje, pois vejo a aposentadoria como um recomeço. Um tempo para dedicar-me à mim, procurando atividades que me deem prazer." (Participante A, TAE).

"É algo que não penso muito, por agora não me preocupa." (Participante G, Docente).

Segundo Kunzler ${ }^{21}$, Espirito Santos, Góes e Chibante ${ }^{22}$, a aposentadoria é um período de transição, um momento de muitas expectativas, que suscita reações ambivalentes. Aposentar-se requer adaptação às mudanças que virão associadas com a nova fase. Os relatos de Docentes e TAE demonstram o sentimento de dedicação e dever cumprido com o serviço público, mas esta nova realidade vem acompanhada da preocupação com a ociosidade, afastamento das amizades, perda de vínculos e o medo de não conseguir desenvolver outra atividade laboral.

\section{Categoria 3 - Planejamento quanto a aposentadoria}

Esta categoria descreve o planejamento dos participantes para a aposentadoria. Dos oito participantes, sete referem já ter algum tipo de planejamento para o novo ciclo da vida e um referiu ainda não ter nenhum tipo de planejamento. Também foi investigado se os participantes tinham conhecimento sobre o Programa de Preparação para Aposentadoria (PPA) disponibilizado pela Instituição. Dos oitos participantes seis referiram conhecer o PPA e dois desconheciam o programa. Dos seis que conhecem o PPA, todos referiram que nunca frequentaram os eventos ou atividades desenvolvidas pelo mesmo.

Aposentar-se, vai muito além do afastamento da atividade laboral, também se trata de uma descoberta, de novas aprendizagens sobre o que fazer do tempo livre, que pensando no aumento da expectativa de vida, fenômeno mundial, os aposentados terão mais tempo para viver a aposentadoria. Dentre as falas, após os entrevistados serem questionados sobre o planejamento e atividades que desejam realizar, apareceram como outras atividades a serem desenvolvidas o trabalho voluntário, cursos, viagens, atividades de lazer, cuidar mais da saúde, pesquisa e escrita, e, nenhum planejamento até agora.

Nas falas dos Participante A e E é possível ver o desejo de realizar trabalho voluntário. 
"[...]desenvolver trabalho voluntário[...]." (Participante A, TAE).

"[...]Realizar atividades sociais e assistenciais sem fins lucrativos." (Participante E, Docente).

O trabalho, faz com que os servidores, como o seu próprio significado da palavra já diz, aquele que serve, sintam-se ativos e contribuintes com a instituição e à população atendida. Assim, podem surgir desejos de continuar contribuindo, com atividades como trabalhos voluntários, fugindo do que está associado à palavra aposentadoria, que é a "inatividade". Sobre a participação de atividades voluntárias, Macedo et al., ${ }^{10}$

[...] parecem esperar do trabalho, após se aposentarem, resultados mais intrínsecos, tais como autonomia, flexibilidade e satisfação na interação interpessoal que pode ser proporcionada por um trabalho voluntário, ou em novos projetos profissionais que não restrinjam a dedicação aos outros espaços da vida (p. 8).

Existe, nos relatos a perspectiva de realizar passeios e viagens de lazer, assim como um momento para cuidar mais da saúde.

"Penso em atividades de lazer como viagens. Cuidar mais da saúde." (Participante C, TAE).

"Viajar muito e estourar o cartão de crédito." (Participante E, Docente).

Ainda, é possível encontrar, além do desejo de participar e desenvolver atividades de beneficência, a vontade de continuar desenvolvendo as mesmas atividades laborais atuais, no caso da docência, pesquisa e escrita, conforme explana o Participante F.

"Viagens, atividades de beneficência, ajuda na organização de entidades, pesquisa e escrita." (Participante F, TAE).

O Participante $\mathrm{F}$, refere que planeja continuar com escrita e pesquisando, ou seja, uma das mesmas funções que desenvolve atualmente. Também, encontrou-se nas falas, aqueles que desejam iniciar um novo trabalho conforme ressaltado pelo Participante $\mathrm{A}, \mathrm{B}$ e $\mathrm{H}$. 
“[...]também tenho interesse em abrir um comércio na área de imóveis."(Participante A, TAE).

"Estou fazendo alguns cursos que pretendo que eu possa transformar em trabalho na minha aposentadoria." (Participante B, TAE).

"Tenho pensado em um novo trabalho/atividade. Não cheguei ainda a qualquer definição." (Participante H, Docente).

A partir das falas dos participantes pode-se observar que estes demonstram dificuldade para desligar-se das atividades laborais. Segundo França ${ }^{15}$, em algumas circunstâncias, o aposentado pode continuar com uma atividade laboral, porém, é importante que exista uma distribuição equilibrada entre o tempo e o trabalho, o cuidado da saúde, relacionamentos, atividades culturais e de lazer, outros interesses como, tempo para si ou para o ócio. Frente as reflexões apresentadas nesta categoria compreendem-se que aposentadoria deve ser trabalhada em uma perspectiva multidimensional e longitudinal, para a qual os sujeitos precisam ser educados no decorrer de todo seu ciclo vital ${ }^{3}$.

\section{CONSIDERAÇÕES FINAIS}

A partir das reflexões apresentadas foi possível compreender a representação do trabalho na vida dos Docentes e TAE, a sua dimensão individual e social, assim como, as percepções sobre o processo de aposentadoria. A heterogeneidade dos discursos, fazem com que seja relevante pensar na preparação que deve existir para uma melhor aceitação do processo e da chegada da aposentadoria, sobre os seus desafios individuais, coletivos e subjetivos.

A não aceitação ou dificuldade de vivenciar a nova etapa, pode estar fortemente ligada ao não planejamento e não preparação que os trabalhadores devem realizar no transcurso da vida. 0 instrumento utilizado para a realização do estudo, permitiu responder aos objetivos, respondendo às questões, evidenciando nos relatos sustentados pelo referencial teórico, a representação positiva dos Docentes e TAE frente à aposentadoria, sendo este considerado um momento de liberdade, oportunidade e qualidade de vida e de traçar um planejamento para as futuras atividades a serem desenvolvidas.

Assim como, aqueles que ainda não estão preparados para o momento, mostrando muita reflexão, dúvidas e questionamentos, referindo o medo e a preocupação do isolamento social e afastamento das pessoas com as quais 
foram construídos fortes laços durante a vida, no ambiente laboral. Mesmo assim, também houveram aqueles que não apresentaram preocupação e tampouco planejamento pós-aposentadoria.

\section{REFERÊNCIAS}

1. Santos F. Identidade e Aposentadoria. São Paulo: E.P.U, 1990.

2. Rodrigues M, Ayabe NH, Lunardelli MCF, Canêo LC. A preparação para a aposentadoria: o papel do psicólogo frente a essa questão. Rev. bras. orientac. Prof. 2005;6(1):53-62.

3. França LHFP, Soares DHP. Preparação para a aposentadoria como parte da educação ao longo da vida. Psicologia: Ciência e Profissão, 2009;29(4):738-751.

4. Vinuto J. A amostragem em bola de neve na pesquisa qualitativa: um debate em aberto. Temáticas. 2014;22(44):203-220.

5. Bardin L. Análise de conteúdo. São Paulo: Edições 70. 2011.

6. Graeff, L. Representações Sociais da Aposentadoria. Textos sobre Envelhecimento. 2002;4(7):19-34.

7. Antunes MH, Soares DHP, Silva N. Orientação para aposentadoria nas organizações: Histórico, gestão de pessoas e indicadores para uma possível associação com a gestão do conhecimento. Perspectivas em Gestão \& Conhecimento. 2015;5(1):43-63.

8. França LHFP, Leite SV, Simões FP, Garcia T, Ataliba P. Análise dos Programas de Preparação para Aposentadoria (PPA) desenvolvidos por instituições públicas brasileiras. Revista Kairós-Gerontologia. 2019;22(1):59-80.

9. França LHFP, Menezes GS, Bendassolli PF, Macêdo LSS. Aposentar-se ou continuar trabalhando? O que influencia esta decisão?. Psicologia Ciência e Profissão. 2013;33(3):548-563. 
10. Macêdo LSS, Bendassolli PF, Torres T. L. Representações sociais da aposentadoria e intenção de continuar trabalhando Universidade Federal do Rio Grande do Norte, Natal/RN, Brasil. Psicologia \& Sociedade. 2017;29:e145010.

11. Venturini DO. Aposentadoria como prêmio ou como castigo: avaliando as peculiaridades dos servidores da UFSM. [Dissertação]. Santa Maria: Pós-Graduação em Gestão de Organizações Públicas, Universidade Federal de Santa Maria, 2013.

12. Panozzo EAL. Percepções de aposentados da serra gaúcha em relação à desvinculação total do trabaIho. [Dissertação]. São Leopoldo: Programa de Pós-Graduação em Psicologia, Universidade do Vale do Rio dos Sinos, 2012.

13. Muniz JA. Programa de Preparação para o Amanhã. Revista Estudos de Psicologia. 1996;2(1):198-204.

14. Lancman S, Sznelwar LI. Cristhophe Dejours: da psicopatologia à psicodinâmica do trabalho. Rio de Janeiro: Editora FIOCRUZ, Brasília: Paralelo, 2008.

15. França LHFP. Repensando aposentadoria com qualidade: um manual para facilitadores de programas de educação para aposentadoria. Rio de Janeiro: UnATI/UERJ, 2002.

16. Moehlecke V, Fonseca TMG, Oliveira AM. Corpos que (se) trabalham: relações éticas na construção de si e do coletivo. Rev. Educação \& Realidade. 2013;38(3):855-871.

17. Rovida MF. Trabalho e identidade social - implicações nas pesquisas em comunicação. Rev. Altejor. Grupo de Estudos Alterjor: Jornalismo Popular e Alternativo (ECA-USP). 2016; 07(01, Ed. 13):183-200.

18. Ashforth B. Role transitions in organizational life: An identity based perspective. Mahwah, N.J: Erlbaum, 2001.

19. Tavares SS, Neri AL, Cupertino AP. Saúde emocional após a Aposentadoria. 2 ed. Campinas: Papirus, 2004. 
20. Zanelli JC, Silva N. Programa de Preparação para Aposentadoria. [S.I.]: Insular, 1996.

21. Kunzler, R.B. A ressignificação da vida cotidiana a partir da aposentadoria e do envelhecimento. (166 f.). Tese de doutorado em Serviço Social. Porto Alegre (RS): Pontifícia Universidade Católica do Rio Grande do Sul. 2009.

22. Espirito Santo, F.H., Góes, P.M.F. de, \& Chibante, C. L.de P. (2014, dezembro). Limites e possibilidades do idoso frente à aposentadoria. Revista Kairós Gerontologia,17(4), pp. 323-335. ISSN 1516-2567. ISSNe 2176-901X. São Paulo (SP), Brasil: FACHS/NEPE/PEPGG/PUC-SP 